\title{
ANALISIS KESALAHAN MENULIS KARANGAN NARASI PADA SISWA KELAS V MIN 1 TANGERANG
}

\author{
Rima Mardiyani Yunita ${ }^{1}$, Intan Sari Ramdhani ${ }^{2}$, Enawar $^{3}$, Sumiyani $^{4}$ \\ 1,2,3,4 Universitas Muhammadiyah Tangerang, Kota Tangerang

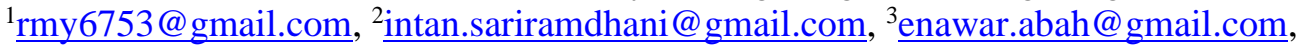 \\ ${ }^{4}$ sumiyaninitura@gmail.com
}

\begin{abstract}
ABSTRAK
Masalah utama yang dikaji dalam penelitian ini adalah analisis kesalahan di dalam karangan narasi siswa kelas V MIN 1 Tangerang. Penelitian ini bertujuan untuk mengetahui kesalahan penulisan huruf kapital dalam menulis karangan narasi dan untuk mengetahui kesalahan penggunaan tanda baca dalam menulis karangan narasi siswa kelas V MIN 1 Tangerang. Metode yang digunakan dalam penelitian ini adalah deskriptif kualitatif dengan menggunakan teknik pengumpulan data berupa observasi, wawancara, dan dokumentasi. Pemeriksaan keabsahan data menggunakan triangulasi. Data dianalisis melalui langkahlangkah pengumpulan data, reduksi data, penyajian data dan penarikan kesimpulan. Responden pada penelitian ini berjumlah 15 orang yakni Guru kelas V, dan 23 siswa kelas V. Berdasarkan hasil penelitian ini adalah (1) Pemakaian Huruf, salah satunya adalah pemakaian huruf kapital, yang di dalamnya terdapat 9 kasus kesalahan; (2) penggunaan tanda baca titik (.) terhadap menulis karangan narasi siswa kelas V MIN 1 Tangerang terdapat 14 kasus kesalahan. Kesalahan penggunaan tanda baca koma (,) terhadap menulis karangan narasi siswa kelas V MIN 1 Tangerang terdapat 10 kasus kesalahan. Kesalahan penggunaan tanda baca tanda tanya (?), Kesalahan penggunaan tanda baca tanda seru (!), dan Kesalahan penggunaan tanda baca tanda petik ("') terhadap menulis karangan narasi siswa kelas V MIN 1 Tangerang terdapat 0 kasus atau tidak terdapat kasus dalam menulis karangan narasi tersebut dikarenakan siswa belum mampu menguasai menulis.
\end{abstract}

Kata Kunci: Analisis Kesalahan, Keterampilan Menulis, Karangan Narasi

\begin{abstract}
The main problem studied in this study is the analysis of errors in the narrative essays of the fifth-grade students of MIN 1 Tangerang. This study aims to find out the errors in writing capital letters in writing narrative essays and to find out errors in using punctuation in writing narrative essays for the fifth-grade students of MIN 1 Tangerang. The method used in this research is descriptive qualitative by using data collection techniques in the form of observation, interviews, and documentation. Check the validity of the data using triangulation. The data were analyzed through the steps of data collection, data reduction, data presentation and drawing conclusions. Respondents in this study amounted to 15 people, namely class $V$ teachers, and 23 students in class $V$. Based on the results of this research are (1) the use of letters, one of which is the use of capital letters, in which there are 9 cases of errors; (2) the use of punctuation marks (.) in writing narrative essays for fifth grade students of MIN 1 Tangerang, there are 14 cases of errors. Errors in the use of comma punctuation (,) in writing narrative essays for class V MIN 1 Tangerang students, there were 10 cases of errors. Errors in using question marks (?), errors in using exclamation marks (!), and Errors in using punctuation marks ("') in writing narrative essays for students of class V MIN 1 Tangerang, there are 0 cases or no cases in writing. The narrative essay is because students have not been able to master writing.
\end{abstract}




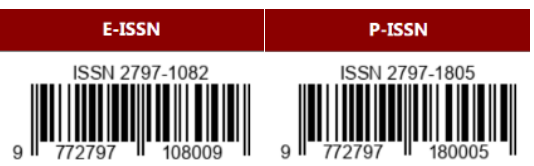

Keywords: Analysis Errors, Skills Writing, Narrative Writing

\section{PENDAHULUAN}

Pendidikan merupakan suatu hal yang penting dalam kebutuhan manusia. Pendidikan selalu mengalami perubahan, perkembangan dan perbaikan sesuai dengan perkembangan di segala bidang kehidupan. Perubahan dan perbaikan dalam bidang pendidikan meliputi berbagai komponen yang terlibat di dalamnya baik itu pelaksanaan pendidikan di lapangan (kompetensi guru dan kualitas pendidik), mutu pendidik, perangkat kurikulum, sarana dan prasarana pendidikan dan mutu manajemen pendidikan termasuk perubahan dalam metode dan strategi pembelajaran yang lebih inovatif. Upaya perubahan dan perbaikan tersebut bertujuan membawa kualitas pendidikan Indonesia ke arah yang lebih baik yang selalu dilakukan dari waktu ke waktu. Pada dasarnnya pendidikan yaitu suatu usaha sadar dalam proses pembelajaran bagi peserta didik untuk dapat melakukan tugas hidupnya secara mandiri supaya dapat bertanggung jawab dalam mengembangkan potensi dirinya untuk membuat manusia lebih kritis dalam berpikir dapat diperoleh secara formal maupun nonformal.

Salah satu pendidikan formal adalah pendidikan Sekolah Dasar yaitu jenjang yang paling dasar di Indonesia. Sekolah Dasar merupakan salah satu jenjang pendidikan yang berlangsung selama 6 tahun, mulai dari kelas 1 sampai kelas 6 yang sangat menentukan pembentukan karakter siswa kedepannya. Di level inilah awal mula anak mendapatkan ilmu pengetahuan dan juga penanaman nilai-nilai yang nantinya akan berguna dalam kehidupanya. Orangtua dan guru bahu-membahu mengarahkan anak agar mampu menjadi pribadi yang cerdas secara akademik, spiritual, dan juga emosionalnya. Pembentukan ini dilakukan secara bertahap dan disesuaikan dengan porsi daya tangkap anak-anak. Pada masa ini anak-anak akan diajarkan berbagai ilmu pengetahuan atau mata pelajaran yang relevan dengan tingkat usianya dan tentunya yang menunjang untuk kelanjutan pendidikannya ke jenjang yang lebih tinggi. Sekolah berlomba-lomba melaksanakan berbagai program sekolah agar dapat memperoleh prestasi sekolah yang baik. Dalam pelaksanaannya, pendidikan sekolah dasar diberikan kepada siswa dengan sejumlah materi mata pelajaran yang harus dikuasainya. mata pelajaran tersebut antara lain pendidikan muatan lokal, seni budaya dan ketarampilan, agama, pendidikan kewarganegaraan, ilmu pengetahuan sosial, ilmu pengetahuan alam dan bahasa Indonesia.

Bahasa Indonesia sebagai bahasa Negara wajib digunakan sebagai bahasa pengantar dalam Pendidikan nasional. Berbahasa Indonesia adalah menggunakan bahasa Indonesia yang sesuai konteks (pembicaraan atau penulisan). Berbahasa Indonesia yang benar adalah menggunakan bahasa Indonesia yang sesuai dengan kaidah (tata bahasa) bahasa Indonesia. Bahasa berperan penting dalam kehidupan manusia. Saat berinteraksi dan berkomunikasi dengan orang lain, manusia menggunakan bahasa yang baik yaitu bahasa lisan maupun tulisan. Kenyataannya, masih banyak terjadi kesalahan pemakaian bahasa di kalangan siswa dalam pendidikan formal. Bahasa adalah alat komunikasi manusia karena bahasa berfungsi dan berperan penting dalam kehidupan manusia. Kemampuan berkomunikasi dalam pengertian yang utuh adalah kemampuan berwacana, yakni 


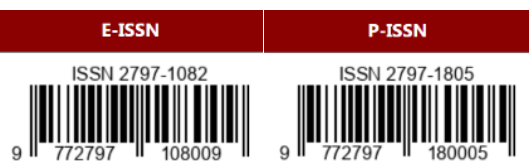

Volume 2 Nomor 1 (Desember 2021 - Februari 2022)

kemampuan memahami atau menghasilkan teks lisan atau tulis yang dinyatakan dalam empat keterampilan berbahasa, yaitu mendengarkan, berbicara, membaca dan menulis. Di dalam aspek keterampilan berbahasa salah satunya keterampilan menulis.

Menulis merupakan keterampilan berbahasa yang sangat kompleks. Seseorang harus mampu berfikir kreatif untuk menghasilkan tulisan yang baik. Banyak orang yang mampu berbicara dengan baik, namun kurang mampu menuangkan ide secara tertulis. Keterampilan menulis masih perlu mendapat perhatian utama dalam pendidikan tingkat dasar sebagai salah satu aspek keterampilan berbahasa, menulis memang dapat dikuasai oleh siapapun yang memiliki kecerdasan yang tinggi. Untuk mengembangkan keterampilan menulis siswa, maka keterampilan menulis telah menjadi kebutuhan pokok dalam kehidupan sehari-hari saat ini. Dalam keadaan bagaimanapun menulis tidak bisa dilepas begitu saja karena merupakan bagian dari kebutuhan hidup manusia yang tak dapat dipisahkan. Peranan menulis pada siswa sangat penting terutama untuk mengasah keterampilan siswa. Keterampilan menulis berkaitan dengan berbagai macam teks, diantaranya teks narasi, teks deskripsi, teks ekposisi, teks argumentasi, dan teks persuatif. Salah satu keterampilan yang perlu dikembangkan saat ini adalah menulis karangan.

Berdasarkan hasil wawancara dengan salah satu guru kelas tinggi mengenai keterampilan menulis pada peserta didik kelas tinggi MIN 1 Tangerang dapat dikatakan masih rendah dikarenakan masih banyak siswa cenderung belum dapat menulis karangan dengan benar. Siswa lebih berorientasi pada hasil karangan, bukan pada proses menulis karangan dengan menggunakan kaidah bahasa Indonesia yang benar. Kesalahan berbahasa disebabkan oleh faktor kompetensi, artinya siswa memang belum memahami sistem linguistik bahasa yang digunakannya. Kesalahan berbahasa biasanya terjadi secara konsisten dan sistematis. Sering dikatakan bahwa kesalahan berbahasa merupakan gambaran terhadap pemahaman siswa akan sistem bahasa yang sedang dipelajarinya. Bila tahap pemahaman siswa tentang sistem bahasa yang sedang dipelajari olehnya ternyata kurang, kesalahan berbahasa tentu sering terjadi. Peneliti belum bisa menyimpulkan keterampilan menulis siswa kelas tinggi di MIN 1 Tangerang sehingga perlu dilakukan penelitian.

Berdasarkan latar belakang yang telah dikemukakan di atas, peulis tertarik untuk meneliti dan mendeskripsikan atau menggambarkan tentang keterampilan menulis siswa kelas tinggi di MIN 1 Tangerang yang berjudul Analisis Kesalahan Menulis Karangan Narasi Pada Siswa Kelas V MIN 1 Tangerang.

\section{METODE PENELITIAN}

Penelitian yang digunakan oleh peneliti ini menggunakan penelitian kualitatif, dengan jenis metode penelitian analisis isi. Penelitian ini dilakukan dengan berdasarkan temuan di lapangan tentang memberikan suatu gambaran apa adanya dan tanpa ada rekayasa yang terjadi di dalam penelitian. Agar peneliti dapat mendeskripsikan secara jelas dan rinci serta mendapatkan data yang mendalami mengenai "Analisis Kesalahan Menulis Karangan Narasi Pada Siswa Kelas V MIN 1 Tangerang”. Hal yang sangat dieprlukan dalam penelitian kualitatif yaitu dapat mengungkapkan suatu data dan 
informasi yang dapat ditarik makna dan konsepnya.

Dalam penelitian model analisis kualitatif yang digunakan adalah model Miles dan Huberman yang meliputi: reduksi data (memilih data yang penting, relevan, dan bermakna dari data yang tidak berguna), sajian deskriptif, (narasi, visual gambar, tabel) yang sistematis dan logis dan penarikan kesimpulan. Instrument penelitiannya dapat berupa tes, pedoman wawancara, pedoman observasi dan pedoman dokumentasi, dan kuesioner. Dalam penelitian ini instrument yang digunakan peneliti yaitu menggunakan tes, wawancara dan dokumentasi. Peneliti menggunakan instrument ini dengan melakukan uji expert judgement dengan Dosen kebahasaan Universitas Muhammadiyah Tangerang.

Dalam penelitian ini, peneliti akan menggunakan teknik analisis data yang telah dipaparkan. Tujuan dari penelitian ini yaitu untuk mengetahui keterampilan menulis dengan adanya kesalahan menulis karangan narasi pada mata pelajaran Bahasa Indonesia siswa kelas V MIN 1 Tangerang. Dengan menggunakan teknik pengumpulan data dan menghasilkan data yang sebenarnya.

\section{HASIL DAN PEMBAHASAN}

Pembahasan hasil penelitian ini dimaksud untuk mengetahui keterampilan menulis dengan adanya kesalahan menulis karangan narasi pada mata pelajaran Bahasa Indonesia siswa kelas V MIN 1 Tangerang. Berdasarkan hasil penelitian pada kelas V, jumlah sampel sebanyak 15 siswa. Yang akan dinilai berdasarkan 6 aspek yaitu penggunaan huruf kapital, penggunaan tanda baca titik, penggunaan tanda baca koma, penggunaan tanda baca tanda tanya, penggunaan tanda baca tanda seru, dan penggunaan tanda baca tanda petik.

Setelah penelitian keterampilan menulis dengan adanya kesalahan menulis karangan narasi pada mata pelajaran Bahasa Indonesia siswa kelas V MIN 1 Tangerang dilakukan, maka dapat disimpulkan bahwa keterampilan menulis karangan narasi pada siswa kelas $\mathrm{V}$ terdapat siswa belum cukup baik dalam keterampilan menulis yang dinilai pada 6 aspek.

\section{KESIMPULAN DAN SARAN \\ Kesimpulan}

Berdasarkan analisis data dan pembahasan dapat disimpulkan bahwa keterampilan menulis siswa kelas $\mathrm{V}$ dalam bercerita sudah cukup baik. Pada 6 aspek yang dinilai yaitu: penggunaan huruf kapital, penggunaan tanda baca titik, penggunaan tanda baca koma, penggunaan tanda baca tanda tanya, penggunaan tanda baca tanda seru, dan penggunaan tanda baca tanda petik, dari 23 siswa terdapat 13 siswa yang belum memenuhi aspek keterampilan menulis dalam karangan narasi.

1. Kesalahan pemakaian huruf kapital (A) terhadap menulis karangan narasi siswa kelas V MIN 1 Tangerang ditemukan sebanyak 9 kasus kesalahan. Kesalahan huruf kapital tersebut disebabkan oleh kesalahan pemakaian huruf kapital pada awal kalimat atau paragraf dan pada saat setelah menggunakan tanda baca titik (.).

2. Kesalahan penggunaan tanda baca titik (.) terhadap menulis karangan narasi siswa kelas V MIN 1 Tangerang terdapat 14 kasus kesalahan. Kesalahan tanda baca titik (.) tersebut disebabkan oleh kesalahan saat tidak menggunakan tanda baca titik (.) diakhir kalimat. Kesalahan penggunaan tanda baca koma (,) terhadap menulis 
karangan narasi siswa kelas V MIN 1 Tangerang terdapat 10 kasus kesalahan. Kesalahan tanda baca koma (,) tersebut disebabkan oleh kesalahan menulis unsurunsur kalimat dan pemisah anak kalimat atau induk kalimat. Kesalahan penggunaan tanda baca tanda tanya (?), Kesalahan penggunaan tanda baca tanda seru (!), dan Kesalahan penggunaan tanda baca tanda petik ("“) terhadap menulis karangan narasi siswa kelas V MIN 1 Tangerang terdapat 0 kasus atau tidak terdapat kasus dalam menulis karangan narasi tersebut dikarenakan siswa belum mampu menguasai menulis.

\section{Saran}

Berdasarkan kesimpulan yang telah diuraikan. Maka peneliti mempunyai beberapa saran untuk beberapa pihak yaitu:

\section{a) Bagi Guru}

Sebagai informasi dan acuan ilmiah bagi guru untuk melaksanakan evaluasi terhadap program yang telah dilakukan, sekaligus mengembangkan dan meningkatkan dalam pembelajaran bahasa Indonesia tentunya keterampilan menulis. Dapat menjadi alat ukur dalam mengetahui kesalahan menulis karangan narasi siswa kelas tinggi dalam pembelajaran bahasa Indonesia sehingga dapat mendukung peningkatkan keterampilan menulis siswa di masa mendatang.

b) Bagi Siswa

Dapat membantu siswa dalam meningkatkan keterampilan menulis karangan narasi dengan baik dan benar. Dapat meningkatkan hasil belajar siswa dalam pelajaran bahasa Indonesia.

\section{c) Bagi Sekolah}

Meningkatkan

kualitas pembelajaran yang berdampak terhadap peningkatan kualitas siswa dalam pembelajaran bahasa Indonesia di sekolah.

\section{d) Bagi Peneliti}

Menambah pengetahuan tentang pentingnya penggunaan tanda baca dalam komunikasi tertulis, serta dapat mengetahui kesalahan dan kemampuan siswa dalam menggunakan huruf kapital dan tanda baca seperti titik, koma, tanda seru dan tanda tanya dalam karangan narasi.

\section{DAFTAR PUSTAKA}

Agustina, L. (2020). Keterampilan Menulis. Yogyakarta: Deepublish Publisher.

Ahsin. (2016). Peningkatan Pembelajaran Keterampilan Menulis Karangan Narasi Dengan Menggunakan Media Audio Visual Dan Metode Quantum Learning. Fakultas Keguruan dan Ilmu Pendidikan Universitas Muria Kudus. Jurnal Refleksi Edukakita No. 2 Vol. 6.

Alfin. (2018). Bahan Ajar Pembelajaran Bahasa Analisis Kesalahan Berbahasa. Surabaya.

Dalman, D. H. (2018). Keterampilan Menulis. Depok: PT Raja Grafindo Persada.

Fadhillah, Hamsanah, Latifah. (2018). Bahan

Ajar Pembelajaran Bahasa Indonesia Kelas Tinggi. Tangerang: Fakultas Keguruan dan Ilmu Pendidikan Universitas Muhammadiyah Tangerang.

Gusti Yarmi. (2017). Pembelajaran Menulis Di Sekolah Dasa. PGSD Universitas Negeri Jakarta. PRESPEKTIF Ilmu Pendidikan No. 31 Vol. 1. 
Herman. (2018). Analisis Kesalahan Berbahasa Di Dalam Karanagan Narasi Siswa Kelas VII SMPN 8 Mataram. Fakultas Keguruan dan Ilmu Pendidikan Universitas Mataram.

Jayadi, U., \& M, M. (2021). Kemampuan Membedakan Imbuhan Dengan Kata Depan Dalam Kalimat Bahasa Indonesia Siswa Kelas X IPA MAN Lombok Barat Tahun Pelajaran 2020/2021. Berajah Journal, 1(1), 1-20. https://doi.org/10.47353/bj.v1i1.16

Magdalena, I., \& Huliatunisa, Y. (2020). Evaluasi Pembelajaran SD. Tangerang: FKIP UMT Press.

Mantasiah R, Y. (2020). Bahan Ajar Pembelajaran Bahasa Analisis Kesalahan Berbahasa. Yogyakarta: Deepublish Publisher.

Mardiyah. (2016). Keterampilan Menulis

Bahasa Indonesia Melalui Kemampuan Mengembangkan Struktur Paragraf. Fakultas: Dakwah IAIN Raden Intan Lampung. Jurnal Pendidikan dan Pembelajaran Dasar No. 2 Vol. 3.

Mawardi. (2019). Desain Pelitian Tindakan

Kelas. Yogyakarta: Deepublish.

Moeleong, L. (2017). Metodelogi Penelitian

Kualitatif. Bandung: PT. Remaja

Rosdakarya.

Oktaviani, Rohmadi, Purwadi. (2018).

Analisis Kesalahan Berbahasa

Indonesia Pada Karangan Eksposisi

Siswa Kelas X MIPA. Fakultas

Keguruan dan Ilmu Pendidikan. Jurnal Basastra No.1 Vol. 6.

Radiatullah. (2020). Analisis Kesalahan

Berbahasa Tataran Sintaksis Pada Penulisan Teks Eksposisi Siswa Kelas VII SMPN 3 SATAP. Fakultas Keguruan dan Ilmu Pendidikan Universitas

Muhammadiyah Mataram.
Rosnaningsih, M. P. (2019). Bahan Ajar Pembelajaran English for Childern bagi siswa SD. Tangerang: Fakultas Keguruan dan Ilmu Pendidikan Universitas Muhammadiyah Tangerang.

Siddik. (2017). Peningkatan Pembelajaran Menulis Karangan Narasi Melali Gambar Berseri Siswa Sekolah Dasar. Universitas Mulamawan. No. 1 (diakses pada tanggal 9 juni 2021)

Sugiono. (2018). Metode Penelitian Kuantitatif, Kualitatif, dan $R \& D$. Bandung: Alfabeta.

Sumarno. (2018). Analisis Isi Dalam Penelitian Pembelajaran Bahasa dan Satra. Universitas Muhammadiyah Kotabumi. Jurnal Esa Vol 18, No. 2

Tantawi, I. (2019). Terampil Berbahasa Indonesia (Untuk Perguruan Tinggi). Jakarta: Kencana.

Wati, Sudigdo. (2019). Keterampilan Menulis Karangan Narasi Sejarah Melalui Model Pembelajaran Mind Mapping Bagi Siswa Sekolah Dasar. Jurnal Prosiding Seminar Nasional PGSD (diakses pada tanggal 3 juni 2021) 